\title{
Trajectories of Limitations in Instrumental Activities of Daily Living in Frail Older Adults With Vision, Hearing, or Dual Sensory Loss
}

\author{
Sigrid Mueller-Schotte, OD, MSc, ${ }^{1,2,3}$ Nicolaas P. A. Zuithoff, PhD, ${ }^{1}$ \\ Yvonne T. van der Schouw, PhD, ${ }^{1}$ Marieke J. Schuurmans, PhD, RN, ${ }^{1,2}$ and \\ Nienke Bleijenberg, PhD, RN ${ }^{1,2}$
}

'Julius Center for Health Sciences and Primary Care, University Medical Center (UMC) Utrecht. ${ }^{2}$ Department for the Chronically III and ${ }^{3}$ Department of Optometry and Orthoptics, University of Applied Sciences Utrecht, The Netherlands.

Address correspondence to: Sigrid Mueller-Schotte, OD, MSc, University of Applied Sciences Utrecht, Heidelberglaan 7, 3584 CS Utrecht, The Netherlands. E-mail: sigrid.mueller-schotte@hu.nl

Received: July 5, 2017; Editorial Decision Date: June 25, 2018

Decision Editor: Anne Newman MD, MPH

\begin{abstract}
Background: This study investigated the trajectories of decline in individual instrumental activities of daily living (IADL) with aging and the effect of hearing loss, vision loss, or dual sensory loss on these trajectories in community-living frail older persons.

Method: This longitudinal population-based study was conducted in 9,319 community-living frail Dutch persons aged 60 years and older. Self-reported hearing loss, vision loss, or dual sensory loss and nine IADL were assessed in 15 studies of the Dutch National Care for the Elderly Program (The Older Persons and Informal Caregivers Survey Minimum Dataset). Probabilities of limitations in IADL, odds ratios (per 5 years) for binary, and rate ratios (per 5 years) for score outcomes were calculated using mixed logistic and negative binomial models with age as the underlying timescale, stratified by sensory loss, and corrected for confounders.

Results: At baseline, the number of IADL limitations was higher in dual sensory loss (2.00 [interquartile range 1.00-4.00]) and vision loss (2.00 [interquartile range 1.00-4.00]) compared to no sensory loss (1.00 [interquartile range 0.00-2.00]) or hearing loss (1.00 [interquartile range 0.00-3.00]). Trajectories of individual IADL showed an increase in limitations in all IADL with age. Household tasks, traveling, shopping, preparing a meal, and walking showed the most rapid decline. Handling finances, traveling, and walking followed a different pattern of decline based on sensory loss status.

Conclusions: The age effect on limitations in IADL appears to be similar across all types of sensory loss, with the exception of handling finances, traveling, and walking. At baseline, persons with self-reported sensory loss had higher levels of self-reported functional limitations. Trajectories depict a decline in IADL competence with age.
\end{abstract}

Keywords: Trajectories, Sensory loss, Everyday competence, Mobility, Community living.

Age-related sensory deficits such as hearing loss (HL) or vision loss (VL) are common chronic conditions in older persons. In community-based studies, prevalence of isolated HL, VL, or concurrent VL and HL, known as dual sensory loss (DSL), ranges between $11.6 \%$ and $43.0 \%, 5 \%$ and $20.6 \%$, and $2.9 \%$ and $38 \%$, respectively, with higher prevalence in older age (1-7). The impact of sensory loss (SL) has been associated with major negative health-related outcomes such as mobility, communication, social participation, depression, cognition, and functional disability; expression and strengths of associations are subject to severity and type of SL (3,7-10).

The ability to function and move around independently in the community is a high priority for older persons. Loss of competence in instrumental activities of daily living (IADL) such as handling finances, grocery shopping, or walking threatens an independent lifestyle and often precedes the loss in competence of self-care activities of daily living such as toileting or bathing (11). Successful completion 
of the individual IADL requires sufficient visual ability (eg preparing a meal) and/or auditory input (eg using the telephone, traveling).

Evidence regarding the impact of VL on IADL and mobility has been provided in cross-sectional $(2,12,13)$ and longitudinal studies $(8,14,15)$. Evidence of HL on IADL and walking has predominantly been assessed cross-sectionally $(2,14,16)$. A recent review on DSL in older adults revealed that studies exploring DSL and IADL competence and walking are scare, mostly cross-sectional, with few studies exploring longitudinal effects and item-specific IADL competence (17). Acknowledging the importance of the different domains of IADL competence, little is known on the effects of SL on individual IADLs over time in community-living frail older adults. This paucity may prevent the development of effective tailored interventions for these persons.

The aim of this study is to investigate trajectories of item-specific IADL decline over age and the (long-term) effect of self-reported HL, VL, or DSL on these trajectories in community-living frail older persons.

\section{Methods}

\section{Study Design and Population}

Data of the Dutch "The Older Persons and Informal Caregivers Survey Minimum Dataset” (TOPICS-MDS), a dynamic public access database of 42 research studies, were used (18). Detailed information on the TOPICS-MDS has been described elsewhere (19).

For this study, studies were eligible if they had data of participants with at least one follow-up assessment at either 6,12,18, or 24 months, and were targeted at frail persons living independently in the community. Participants were eligible if they were 60 years of age or older and had complete baseline data on all variables relevant to this research question. This resulted in a final data set (derived January 2016) consisting of 15 studies and data of 9,319 frail older persons (Figure 1 and Supplementary Table 1).

Ethical approval for the fully anonymized data set was integrated in the individual studies. Studies using TOPICS-MDS data were exempted from ethical review (Radboud University Medical Center Ethical Committee review reference number CMO: 2012/120).

\section{Measurements}

\section{Determinants}

Sensory loss

Self-reported $H L$ and $V L$ were assessed by asking the participant "Place a tick next to the illnesses and conditions ([hearing problem] or [vision problem]) that you have at the moment or have had in the past 12 months. You can select more than one answer." Both items were scored with two answer categories "absent" $(0)$ and "present" (1). Subsequently, a variable $S L$ was constructed for baseline assessment with four categories: no HL and no VL (no sensory loss [NSL]) (0), isolated HL (1), isolated VL (2) and DSL (both HL and VL) (3).

\section{Outcomes}

\section{Primary Outcomes}

Ability to perform IADL

At baseline and follow-up, self-reported activities of daily living (ADL) and IADL were assessed using the modified KATZ-15 ADL and IADL questionnaire (20). Nine IADL items were measured: grooming, transportation, grocery shopping, preparation of a meal, telephone use, household, handling medications, managing money,

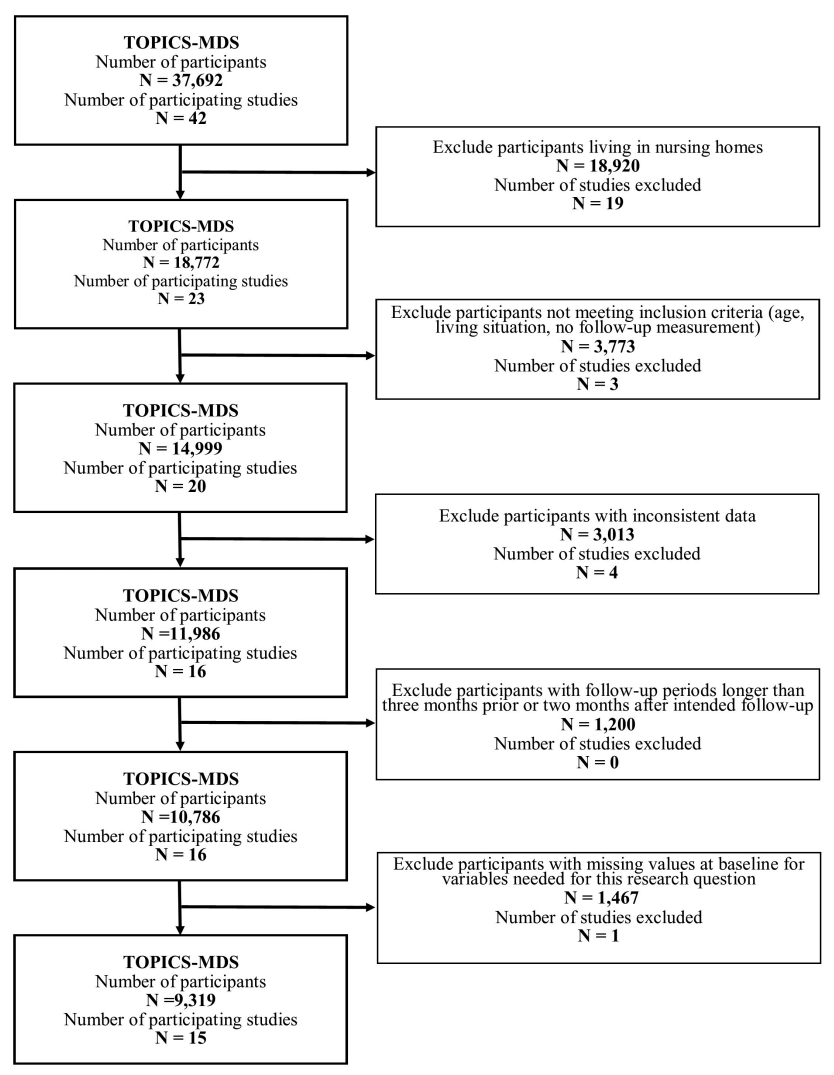

Figure 1. Flow of participants and study inclusion ( $N=$ number;TOPICS-MDS $=$ The Older Persons and Informal Caregivers Survey - Minimum Dataset).

and walking. Participants were asked "Do you need help with [item]?" Each item had two answer categories: "no" $(0)$ and "yes" (1) (20).

\section{Demographics and Other Variables}

At baseline and follow-up, demographic information on age, gender, and marital status was obtained using self-reported questionnaires. At baseline, information on educational level, socioeconomic status, and the number of 14 high-impact chronic health conditions was obtained. For details, see Supplementary Material.

\section{Statistical Analysis}

Characteristics of the participants were reported as frequencies and percentages for categorical variables and means and standard deviations or medians and interquartile ranges for continuous variables where applicable.

TOPICS-MDS is a pooled data set of individual-level information incorporating data of studies with different study designs and sampling frameworks. We used one-step, in particular, mixed (multilevel) models with three levels (time, person, and study), where the study is the highest level of clustering. Individual participant data were used. This allowed for nesting within study and provided estimates that are precision weighted according to the sample size of each study.

Mixed logistic regression models for dichotomous outcomes and mixed negative binomial regression models for score outcomes were used to estimate the association between age and each of the IADL items. To account for dependency across the repeated measurements 
within the same participant during follow-up, a standard covariance components matrix was included (21-23) and a random intercept to account for differences between studies. The models were fitted on an age scale (per 5 years), corrected for determinants reported to be associated with disability, such as gender, education, socioeconomic status, and the number of chronic diseases (24). These models were used to estimate odd ratios (ORs) and rate ratios (RRs) with $95 \%$ confidence intervals (CIs) and to estimate predicted probabilities for individual IADL for each 5 -year age group and SL group. For each IADL item, the interaction between age group and SL was tested to determine whether the association of these factors differed according to age (additional information in Supplementary Material). Statistical significance levels were set at .05 . All analyses were performed using the statistical program IBM SPSS Statistics for Windows (Version 24.0; IBM Corp.) and SAS version 9.4 (SAS Institute, Inc., Cary, NC).

\section{Results}

Table 1 shows the baseline characteristics of all participants stratified by SL. Most of the 9,319 participants reported NSL $(N=4,150$,
$44.5 \%$ ) whereas $1,693(18.2 \%)$ participants reported DSL. Age was higher with an increasing number of SL (Table 1). The number of reported IADL limitations was the highest for participants with DSL (2.00 [interquartile range 1.00-4.00]) and VL (2.00 [interquartile range 1.00-4.00]). Figure 2 depicts the prevalence of the number of IADL limitations over a 2 -year period. Almost $75 \%$ reported no limitation in IADL at age 60-64 years; by age 75-79 years, this percentage was $48 \%$, and in those $\geq 90$ years, $6 \%$ reported no limitation in any IADL.

\section{Trajectories of IADL}

Supplementary Table 2 of the supplement provides an overview of the number of participants in the analysis per IADL item and SL and time of measurement. Figure 3A-J displays the trajectories of IADL limitations by age and SL. Trajectories of the individual IADL depict an increased probability in IADL limitations with age. Five IADL have the highest probability of decline: household tasks (Figure $3 \mathrm{C}$ ), traveling (Figure $3 \mathrm{H}$ ), shopping (Figure 3F), preparing a meal (Figure 3D), and walking (Figure 3I). Difficulties with household tasks, traveling, and shopping show the most rapid decline with

Table 1. Baseline Characteristics of Participants

\begin{tabular}{|c|c|c|c|c|c|}
\hline & All Participants & No Sensory Loss & Hearing Loss & Vision Loss & $\begin{array}{l}\text { Dual Sensory } \\
\text { Loss }\end{array}$ \\
\hline & $(N=9,319)$ & $(N=4,150)$ & $(N=1,945)$ & $(N=1,531)$ & $(N=1,693)$ \\
\hline Age $($ mean $\pm S D)$ & $78.58 \pm 6.60$ & $76.87 \pm 6.16$ & $79.55 \pm 6.16$ & $78.60 \pm 6.71$ & $81.67 \pm 6.53$ \\
\hline \multicolumn{6}{|l|}{ Gender $(N ; \%)$} \\
\hline Male & $3,802(40.8)$ & $1,694(40.8)$ & $991(51.0)$ & $462(30.2)$ & $655(38.7)$ \\
\hline Female & $5,517(59.2)$ & $2,465(59.2)$ & $954(49.0)$ & $1,069(69.8)$ & $1,038(61.3)$ \\
\hline \multicolumn{6}{|l|}{ Education $(N ; \%)$} \\
\hline Low $^{\dagger}$ & $2,993(32.1)$ & $1,270(30.6)$ & $618(31.8)$ & $522(34.1)$ & $538(34.4)$ \\
\hline Medium $^{\ddagger}$ & $5,301(56.9)$ & $2,391(57.6)$ & $1,111(57.1)$ & $847(55.3)$ & $952(56.2)$ \\
\hline High $^{\$}$ & $1,025(11.0)$ & $489(11.8)$ & $216(11.1)$ & $162(10.6)$ & $158(9.3)$ \\
\hline \multicolumn{6}{|l|}{ Marital status $(N ; \%)$} \\
\hline Married & $4,675(50.2)$ & $2,262(54.5)$ & $1,048(53.9)$ & $660(43.1)$ & $705(41.6)$ \\
\hline Divorced & $609(6.5)$ & $264(6.4)$ & $97(5.0)$ & $132(8.6)$ & $116(6.9)$ \\
\hline Widow/widower/partner deceased & $3,403(36.5)$ & $1,345(32.4)$ & $700(36.0)$ & $608(39.7)$ & $750(44.3)$ \\
\hline Single & $475(5.1)$ & $205(4.9)$ & $71(3.7)$ & $104(6.8)$ & $95(5.6)$ \\
\hline Sustainable living/unmarried & $157(1.7)$ & $74(1.8)$ & $29(1.5)$ & $27(1.8)$ & $27(1.6)$ \\
\hline \multicolumn{6}{|l|}{ Living situation $(N ; \%)$} \\
\hline Independent alone & $4,405(47.3)$ & $1,783(43.0)$ & $843(43.3)$ & $832(54.3)$ & $947(55.9)$ \\
\hline Independent with others & $4,914(52.7)$ & $2,367(57.0)$ & $1,102(56.7)$ & $699(45.7)$ & $746(44.1)$ \\
\hline Socioeconomic status $2010($ mean $\pm S D)$ & $0.07 \pm 1.01$ & $0.14 \pm 1.03$ & $0.08 \pm 1.01$ & $0.00 \pm 1.00$ & $-0.06 \pm 0.98$ \\
\hline Chronic diseases (median $\pm \mathrm{IQR}$ ) & $2.00[1.00-3.00]$ & $1.00[0.00-2.00]$ & $2.00[1.00-3.00]$ & $2.00[1.00-3.00]$ & $3.00[1.00-4.00]$ \\
\hline $\begin{array}{l}\text { Number of (I)ADL limitations (KATZ-15, total) } \\
\text { (median [IQR]) }\end{array}$ & $2.00[0.00-4.00]$ & $1.00[0.00-3.00]$ & $1.00[0.00-4.00]$ & $2.00[1.00-5.00]$ & $3.00[1.00-5.00]$ \\
\hline $\begin{array}{l}\text { Number of ADL limitations (total 0-6) (median } \\
{[\text { IQR]) }}\end{array}$ & $0.00[0.00-1.00]$ & $0.00[0.00-1.00]$ & $0.00[0.00-1.00]$ & $0.00[0.00-1.00]$ & $0.00[0.00-1.00]$ \\
\hline $\begin{array}{l}\text { Number of IADL limitations (total 0-9) (median } \\
{[\text { IQR]) }}\end{array}$ & $1.00[0.00-3.00]$ & $1.00[0.00-2.00]$ & $1.00[0.00-3.00]$ & $2.00[1.00-4.00]$ & $2.00[1.00-4.00]$ \\
\hline Difficulties grooming YES $(N ; \%)$ & $215(2.3)$ & $75(1.8)$ & $36(1.9)$ & $39(2.5)$ & $65(3.8)$ \\
\hline Difficulties handling finances YES $(N ; \%)$ & $2,120(22.7)$ & $980(23.6)$ & $404(20.8)$ & $350(22.9)$ & $386(22.8)$ \\
\hline Difficulties with household tasks YES (N; \%) & $5,022(53.9)$ & $1,803(43.4)$ & $1,009(51.9)$ & $1,013(66.2)$ & $1,197(70.7)$ \\
\hline Difficulties preparing a meal YES (N; \%) & $1,724(18.5)$ & $590(14.2)$ & $376(19.3)$ & $330(21.6)$ & $428(25.3)$ \\
\hline Difficulties handling medication YES $(N ; \%)$ & $764(8.2)$ & $245(5.9)$ & $158(8.1)$ & $154(10.1)$ & $207(12.2)$ \\
\hline Difficulties with shopping YES (N; \%) & $2,490(26.7)$ & $850(20.5)$ & $44(23.0)$ & $544(35.5)$ & $648(38.3)$ \\
\hline Difficulties using phone YES (N; \%) & $379(4.1)$ & $97(2.3)$ & $104(5.3)$ & $55(3.6)$ & $123(7.3)$ \\
\hline Difficulties with traveling YES $(N ; \%)$ & $2,830(30.4)$ & $940(22.7)$ & $496(25.5)$ & $617(40.3)$ & 777 (45.9) \\
\hline Difficulties with walking YES $(N ; \%)$ & $2,614(28.1)$ & $870(21.0)$ & $516(26.5)$ & $554(36.4)$ & $674(39.8)$ \\
\hline
\end{tabular}

Notes: $\mathrm{ADL}=$ activities of daily living; IADL = instrumental activities of daily living; IQR = interquartile range; $N=$ number; $S D=$ standard deviation.

${ }^{\dagger}$ Less than six classes of primary school, six primary school classes, more than primary school/primary school with uncompleted further education. ${ }^{\ddagger}$ Practical

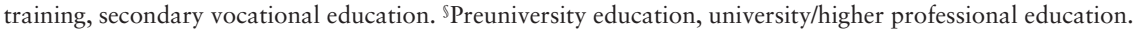




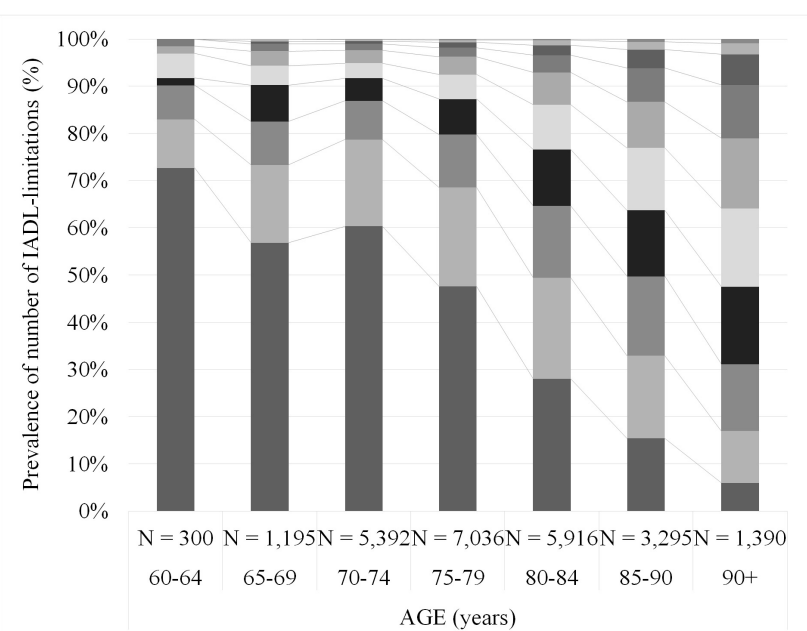

- IADL-limitations $0=$ IADL-limitations 1 IADL-limitations 2 IADL-limitations 3 IADL-limitations $4=$ IADL-limitations 5 IADL-limitations 6 IADL-limitations 7 IADL-limitations 8 IADL-limitations 9

Figure 2. Prevalence of the number of limitations in self-reported activities of daily living (IADL) over a 2-year period stratified by age.

age, whereas difficulties with preparing a meal and walking have an initial gentle decline at younger old age, with increase in decline after age 80 years.

Trajectories on difficulties handling finances (Figure 3B) and medications (Figure 3E) indicate a gentle decline up to age 85 years with a slight increase thereafter. However, participants with NSL barely decline in handling finances over the entire age range. Grooming (Figure 3A) and telephone use (Figure 3G) appear to be unaffected up to age 90 years, with more than $80 \%$ being able to perform these activities at age 100 years. Trajectories in the number of IADL limitations suggest a steady decline up to age 90 years, leveling off thereafter.

\section{Age Effect on Groups of SL and IADL Limitation}

Table 2 shows the effect of age (per 5 years) for each SL group adjusted for gender, education, socioeconomic status, and the number of chronic diseases.

The age effect on difficulties handling finances was higher for all groups with SL compared to without SL: HL (OR = 1.38 [95\% $\mathrm{CI}=1.27 ; 1.50]), \mathrm{VL}(\mathrm{OR}=1.40[95 \% \mathrm{CI}=1.31 ; 1.49]), \mathrm{DSL}$ $(\mathrm{OR}=1.48[95 \% \mathrm{CI}=1.38 ; 1.58])$ versus $\mathrm{NSL}(\mathrm{OR}=1.15[95 \%$ $\mathrm{CI}=1.08 ; 1.23]$ ).

Concerning difficulties with household tasks, the age effect was highest for $\mathrm{HL}(\mathrm{OR}=1.99[95 \% \mathrm{CI}=1.86 ; 2.13])$ and lowest for NSL $(\mathrm{OR}=1.75[95 \% \mathrm{CI}=1.67 ; 1.83])$. VL and DSL had similar point estimates as NSL.

The age effect on difficulties with traveling and shopping was highest for $\mathrm{HL}\left(\mathrm{OR}_{\text {Travel }}=1.89[95 \% \mathrm{CI}=1.76 ; 2.03]\right.$ and $\left.\mathrm{OR}_{\text {Shopping }}=1.68[95 \% \mathrm{CI}=1.56 ; 1.80]\right)$ and lowest for $\mathrm{VL}$ $\left(\mathrm{OR}_{\text {Travel }}=1.43[95 \% \mathrm{CI}=1.36 ; 1.51]\right.$ and $\mathrm{OR}_{\text {Shopping }}=1.39[95 \%$ $\mathrm{CI}=1.32 ; 1.47])$. Point estimates of DSL and NSL lay between HL and VL.

Concerning difficulties using the telephone, handling medication, and grooming, the age effect was highest for NSL $\left(\mathrm{OR}_{\text {Telephone }}=1.61\right.$ $[95 \% \mathrm{CI}=1.42 ; 1.83], \mathrm{OR}_{\text {Medication }}=1.60[95 \% \mathrm{CI}=1.47 ; 1.75]$, and $\left.\mathrm{OR}_{\text {Grooming }}=1.78[95 \% \mathrm{CI}=1.54 ; 2.05]\right)$ and lowest for $\mathrm{VL}$ $\left(\mathrm{OR}_{\text {Telephone }}=1.13[95 \% \mathrm{CI}=0.98 ; 1.31], \mathrm{OR}_{\text {Medication }}=1.30[95 \%\right.$
$\mathrm{CI}=1.20 ; 1.40]$, and $\left.\mathrm{OR}_{\text {Grooming }}=1.33[95 \% \mathrm{CI}=1.15 ; 1.54]\right)$. Point estimates for HL and DSL lay between NSL and VL.

The age effect on difficulties preparing a meal was highest for DSL $(\mathrm{OR}=1.66[95 \% \mathrm{CI}=1.56 ; 1.77])$ and lowest for VL $(\mathrm{OR}=1.38[95 \% \mathrm{CI}=1.38 ; 1.46])$. Point estimates for HL and NSL lay between DSL and VL.

Concerning the limitations in the number of IADL, the age effect was higher for NSL ( $R R=1.41[95 \% \mathrm{CI}=1.30 ; 1.52]$ ) or HL $(\mathrm{RR}=1.43[95 \% \mathrm{CI}=1.28 ; 1.60])$ and lower for $\mathrm{VL}(\mathrm{RR}=1.24$ $[95 \% \mathrm{CI}=1.13 ; 1.37])$ or DSL $(\mathrm{RR}=1.27[95 \% \mathrm{CI}=1.15 ; 1.41])$.

\section{Discussion}

In this study, the effect of self-reported HL, VL, or DSL on the trajectories of self-reported limitations in IADL with aging in communityliving frail older persons was investigated. We observed that people with SL at baseline had higher levels of functional limitations at baseline. Trajectories on IADL limitations depict a decline in IADL competence with age that appears to be of similar pace for all SL groups, except for handling finances, traveling, and walking.

Looking at the individual trajectories of IADL items, household tasks, traveling, grocery shopping, preparing a meal, and walking were activities with the most rapid decline, with household tasks having the highest probability of decline in the younger-old with VL (0.18) and DSL (0.19). Furthermore, handling finances was almost unaffected in the NSL group over the entire age range contrary to a decline for those with SL. This is in-line with a longitudinal study on IADL disability and SL, which found an increased risk of difficulties handling finances for persons with VL or DSL, but not HL (25). Some methodological aspects must be considered to appreciate the results. First, we used self-reported measures rather than objective measures to assess sensory function and IADL competence. Although both strong $(26,27)$ and weak (7) correlations between self-reported and objective measures have been reported, subjective measures can be of advantage as they encompass a subjective component of functional capability that is not provided by objective measures. Restricting to objective measures, ie visual acuity or pure-tone audiometry, ignores other visual or auditory influences such as contrast sensitivity or word-in-noise. Second, the use of survey data may have affected our results, as no information on the severity of or changes in sensory or health status nor the use of vision or hearing aids was available. Furthermore, nuances in functioning and health status could not be accounted for by limiting answer categories to yes/no lacking discriminative ability (28). This may have led to an underestimation of trajectories for persons with severe or changes in SL. However, one study found no difference in IADL limitations between hearing-aid users and nonusers after 5 years (29) whereas a small study on 17 individuals with 6 months follow-up suggests improvement in telephone use after wearing a hearing aid (30). Third, the heterogeneity within TOPICS-MDS as a pooled data set of different studies varying in population size and reporting levels across variables may be of concern. However, statistical strategies frequently used for the analysis of individual participant data from various data sources were applied and random effects by study were used to account for differences between studies $(21,22,31)$. Yet, differences in results due to modeling approaches and choice of statistical models have been reported $(31,32)$. Fourth, survival and selection bias due to a mortality effect may have led to a biased estimation of the trajectories of decline.

The strengths of our study are the evaluation of NSL, HL, VL, along with DSL, and the long-term impact on individual IADL items. 

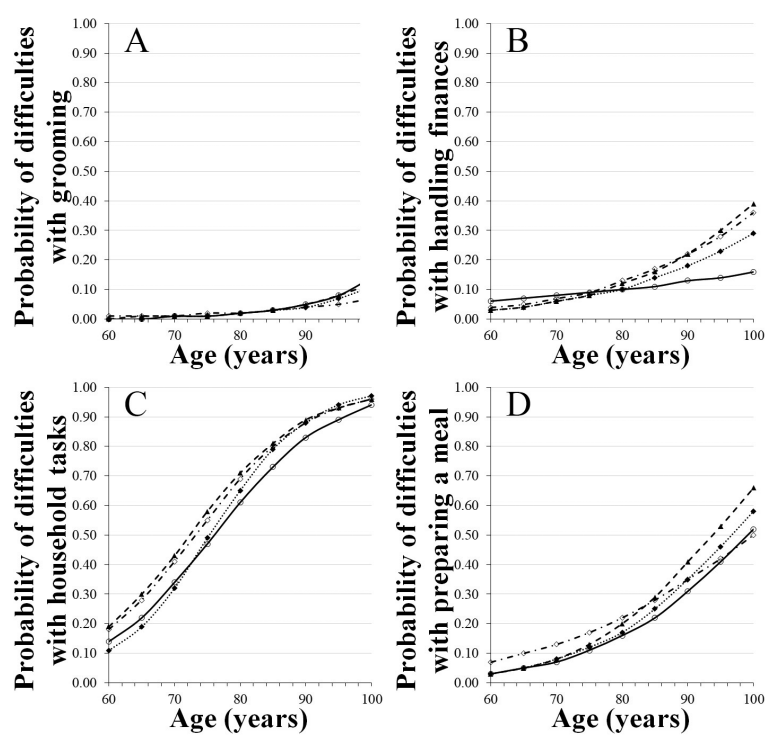

- No sensory loss $\cdot$ Hearing loss $\cdot$ Vision loss $•$ Dual sensory loss -No sensory loss Hearing loss - - Vision loss - -Dual sensory loss
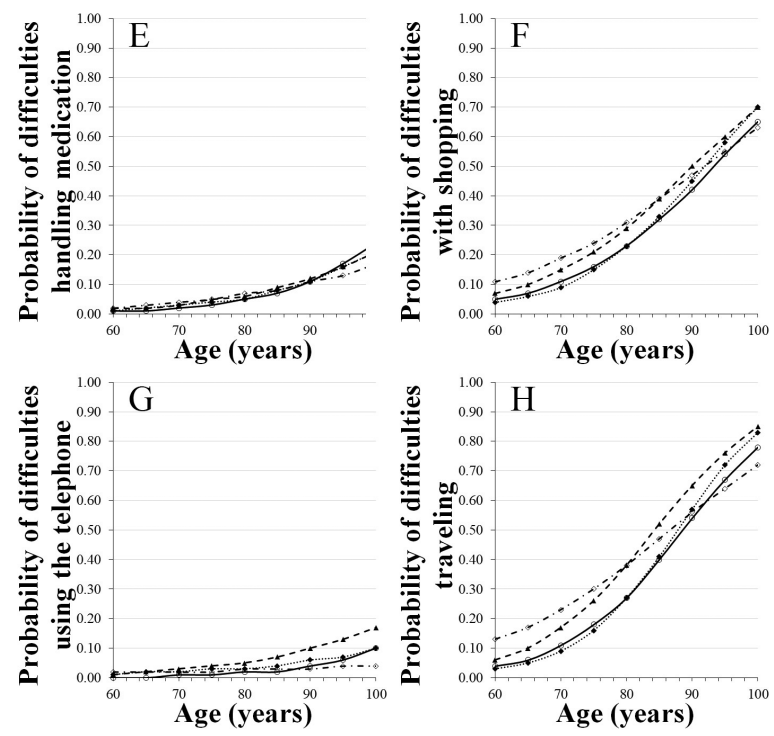

No sensory loss $\cdot$ Hearing loss $\bullet$ Vision loss $•$ Dual sensory loss -No sensory loss - Hearing loss - - Vision loss--Dual sensory loss

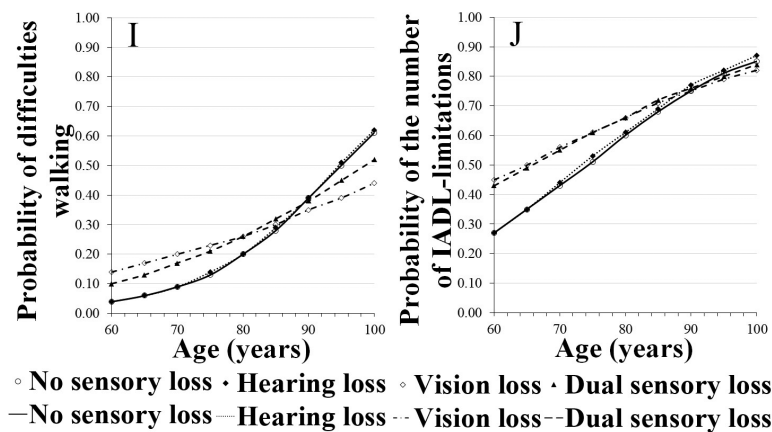

Figure 3. (A-I) Trajectories of limitations in individual activities of daily living (IADL) by age and sensory problem. (J) Trajectories of limitations in the number of IADL items by age and sensory problem.
Moreover, the large number of frail participants living in the community and the broad age range of 60-100 years contribute to an in-depth understanding of the aging process in this population. Furthermore, IADL were chosen as an early indicator of decline as they often precede decline in basic activities of daily livings (11). The evaluation of IADL limitations at item level rather than the presence of IADL limitations provided new insight in the item-specific decline with the goal of developing future targeted interventions. Because the analysis was conducted on an age scale, we were able to depict the trajectories on IADL items and clearly visualize the age component on the decline.

Participants reporting SL had higher levels of IADL limitations at baseline, but the effect of SL was subsiding over time, except for handling finances, traveling, and walking. This is in-line with other studies that found a higher prevalence of IADL limitations at baseline but a diminished effect of SL over time $(3,8)$.

Some of our findings were unexpected: grooming, handling medication, and telephone use appeared to be minimally affected by SL throughout the entire age range; yet, the effect of age varied between SL groups. The gentle decline in telephone use may be due to technological advances, ie availability and use of hearing and vision aids, or specialized (electronic) devices for visually or auditory impaired enhancing ease of telephone use $(30,33)$, factors that we were unable to account for.

Furthermore, the age effect on isolated VL and IADL limitations appeared to be lower compared to NSL for several activities. In addition, trajectories on difficulties with walking and the lower point estimates of the age-SL interaction in VL or DSL compared to NSL or HL were unexpected as most cross-sectional studies indicate an up to fourfold increased risk of walking difficulties due to VL or DSL $(2,34)$. We hypothesize that older adults with VL and/or HL at younger old age possibly adapt to the situation by various strategies or acceptance of the situation, whereas persons with onset of disease at older age may be troubled by the new situation. This hypothesis is supported by studies in older adults with SL that suggest varying resilience and adaption over time $(35,36)$. Other explanations may be the wording of SL assessment or the fact that we were unable to account for changes in SL throughout the follow-up as participants may have had improvement in vision or hearing, by, ie cataract surgery, use of hearing aids, both readily available to all persons living in the Netherlands.

The results of this study suggest that the longitudinal influence of both types of SL either isolated or concurrent on the decline in IADL functioning is similar to those without SL, with the exception of handling medication, traveling, and walking. However, the effect of age differed per IADL activity and SL group. This is in contrast with other studies that found stronger associations for VL and/or DSL with IADL limitations over time than NSL $(3,8,15)$. A study on $\mathrm{HL}$ and physical function found a $60 \%$ increased risk of IADL limitations and walking with each $25-\mathrm{dB}$ increase in hearing deficit (16). However, the operationalization of IADL and SL is not comparable to our study as a variety of IADL definitions was used varying between any type of limitations to change in disability and questionnaires or objective measurements for SL $(3,8,15,16)$. Reasons for no significant difference between SL groups could be related to coping mechanisms through cognitive resources $(35,36)$ or use of technology (33); however, the latter may be limited to the younger old. Inability to account for changes in SL status may have prevented significant differences between SL groups.

We observed that four of the five IADL items (traveling, grocery shopping, preparing a meal, and walking) with the most rapid 
Table 2. Odds Ratios and Rate Ratios of the Interaction Between Age (Per 5 Years) and Sensory Loss for Each Group of Sensory Loss Separately

\begin{tabular}{|c|c|c|c|}
\hline IADL Activity & Sensory Loss & $\mathrm{OR}^{\dagger}$ & $95 \% \mathrm{CI}$ \\
\hline \multirow[t]{4}{*}{ Grooming } & NSL & 1.78 & $(1.54 ; 2.05)$ \\
\hline & $\mathrm{HL}$ & 1.61 & $(1.33 ; 1.96)$ \\
\hline & $\mathrm{VL}$ & 1.33 & $(1.15 ; 1.54)$ \\
\hline & DSL & 1.58 & $(1.36 ; 1.82)$ \\
\hline \multirow[t]{4}{*}{ Managing finances } & NSL & 1.15 & $(1.08 ; 1.23)$ \\
\hline & $\mathrm{HL}$ & 1.38 & $(1.27 ; 1.50)$ \\
\hline & $\mathrm{VL}$ & 1.40 & $(1.31 ; 1.49)$ \\
\hline & DSL & 1.48 & $(1.38 ; 1.58)$ \\
\hline \multirow[t]{4}{*}{ Household tasks } & NSL & 1.75 & $(1.67 ; 1.83)$ \\
\hline & HL & 1.99 & $(1.86 ; 2.13)$ \\
\hline & $\mathrm{VL}$ & 1.78 & $(1.68 ; 1.89)$ \\
\hline & DSL & 1.79 & $(1.67 ; 1.91)$ \\
\hline \multirow[t]{4}{*}{ Preparing a meal } & NSL & 1.55 & $(1.46 ; 1.64)$ \\
\hline & $\mathrm{HL}$ & 1.60 & $(1.48 ; 1.72)$ \\
\hline & $\mathrm{VL}$ & 1.38 & $(1.30 ; 1.46)$ \\
\hline & DSL & 1.66 & $(1.56 ; 1.77)$ \\
\hline \multirow[t]{4}{*}{ Handling medication } & NSL & 1.60 & $(1.47 ; 1.75)$ \\
\hline & HL & 1.48 & $(1.33 ; 1.65)$ \\
\hline & $\mathrm{VL}$ & 1.30 & $(1.20 ; 1.40)$ \\
\hline & DSL & 1.41 & $(1.30 ; 1.53)$ \\
\hline \multirow[t]{4}{*}{ Grocery shopping } & NSL & 1.57 & $(1.50 ; 1.65)$ \\
\hline & $\mathrm{HL}$ & 1.68 & $(1.56 ; 1.80)$ \\
\hline & VL & 1.39 & $(1.32 ; 1.47)$ \\
\hline & DSL & 1.54 & $(1.45 ; 1.63)$ \\
\hline \multirow[t]{4}{*}{ Using the telephone } & NSL & 1.61 & $(1.42 ; 1.83)$ \\
\hline & $\mathrm{HL}$ & 1.32 & $(1.17 ; 1.49)$ \\
\hline & $\mathrm{VL}$ & 1.13 & $(0.98 ; 1.31)$ \\
\hline & DSL & 1.39 & $(1.25 ; 1.55)$ \\
\hline \multirow[t]{4}{*}{ Traveling } & NSL & 1.76 & $(1.67 ; 1.85)$ \\
\hline & HL & 1.89 & $(1.76 ; 2.03)$ \\
\hline & VL & 1.43 & $(1.36 ; 1.51)$ \\
\hline & DSL & 1.74 & $(1.64 ; 1.85)$ \\
\hline \multirow[t]{4}{*}{ Walking } & NSL & 1.59 & $(1.51 ; 1.68)$ \\
\hline & $\mathrm{HL}$ & 1.60 & $(1.49 ; 1.72)$ \\
\hline & $\mathrm{VL}$ & 1.22 & $(1.15 ; 1.29)$ \\
\hline & DSL & 1.33 & $(1.25 ; 1.41)$ \\
\hline IADL activity & SL & $\mathrm{RR}^{\dagger}$ & $95 \% \mathrm{CI}$ \\
\hline \multirow[t]{4}{*}{ Number of IADL limitations (0-9) } & NSL & 1.41 & $(1.30 ; 1.52)$ \\
\hline & $\mathrm{HL}$ & 1.43 & $(1.28 ; 1.60)$ \\
\hline & $\mathrm{VL}$ & 1.24 & $(1.13 ; 1.37)$ \\
\hline & DSL & 1.27 & $(1.15 ; 1.41)$ \\
\hline
\end{tabular}

Notes: $\mathrm{CI}=$ confidence interval; DSL $=$ dual sensory loss; $\mathrm{HL}=$ hearing loss; IADL = instrumental activities of daily living; OR = odds ratio of the interaction between age (per 5 years) and sensory loss; RR = rate ratio of the interaction between age (per 5 years) and sensory loss; $\mathrm{SL}=$ sensory loss; $\mathrm{VL}=$ vision loss.

${ }^{\dagger}$ Adjusted for gender, education, socioeconomic status, and the number of chronic diseases.

decline need dual sensory input for successful completion. In our study, these were also the items with the highest probabilities to be lost over the age range. Part of our data supports earlier evidence that VL seems to weight more than isolated HL or DSL $(8,37)$, exemplified by the higher predicted probabilities for the VL group at younger old age for several IADL. However, the effect seems to subside after the age of 85 years.

More longitudinal research on the impact of SL on IADL limitations is needed incorporating objective and subjective measures as well as severity of functional loss. Furthermore, the use of vision and hearing devices and other technology as well as context and coping strategies should be considered to unravel their effect on the trajectories of individual IADL items.

\section{Conclusion}

The effects of age on limitations in individual IADL appear to be similar across all types of SL, with the exception of handling finances, traveling, and walking. At baseline, persons with self-reported SL had higher levels of self-reported functional limitations. Trajectories depict a decline in IADL competence with age. Household tasks, traveling, grocery shopping, preparing a meal, and walking showed the most rapid decline. Future longitudinal research should include severity of SL, technology use as well as context and coping strategies and IADL capacity.

\section{Supplementary Material}

Supplementary data are available at The Journals of Gerontology, Series A: Biological Sciences and Medical Sciences online.

\section{Funding}

This work was supported by ZonMW, Organization for Health Research and Development, The Netherlands (grant number 60-63300-98-406).

\section{Acknowledgements}

The authors thank all TOPICS-MDS Consortium members and all participants of the individual research studies contributing to the Dutch National Care for the Elderly Programme for their contribution this research.

\section{Conflict of Interest}

None declared.

\section{References}

1. Chou KL. Combined effect of vision and hearing impairment on depression in older adults: evidence from the English Longitudinal Study of Ageing. $J$ Affect Disord. 2008;106:191-196. doi:10.1016/j.jad.2007.05.028.

2. Crews JE, Campbell VA. Vision impairment and hearing loss among community-dwelling older Americans: implications for health and functioning. Am J Public Health. 2004;94:823-829.

3. Brennan M, Su YP, Horowitz A. Longitudinal associations between dual sensory impairment and everyday competence among older adults. $J$ Rehabil Res Dev. 2006;43:777-792.

4. Swenor BK, Muñoz B, West SK. Does visual impairment affect mobility over time? The Salisbury Eye Evaluation Study. Invest Ophthalmol Vis Sci. 2013;54:7683-7690. doi:10.1167/iovs.13-12869.

5. Grue EV, Kirkevold M, Ranhoff AH. Prevalence of vision, hearing, and combined vision and hearing impairments in patients with hip fractures. J Clin Nurs. 2009;18:3037-3049. doi:10.1111/j.1365-2702. 2009.02856.x.

6. Dupuis K, Pichora-Fuller MK, Chasteen AL, Marchuk V, Singh G, Smith SL. Effects of hearing and vision impairments on the Montreal Cognitive Assessment. Neuropsychol Dev Cogn B Aging Neuropsychol Cogn. 2015;22:413-437. doi:10.1080/13825585.2014.968084.

7. Haanes GG, Kirkevold M, Horgen G, Hofoss D, Eilertsen G. Sensory impairments in community health care: a descriptive study of hearing and vision among elderly Norwegians living at home. J Multidiscip Healthc. 2014;7:217-225. doi:10.2147/JMDH.S58461.

8. Wahl HW, Heyl V, Drapaniotis PM, et al. Severe vision and hearing impairment and successful aging: a multidimensional view. Gerontologist. 2013;53:950-962. doi:10.1093/geront/gnt013. 
9. Fischer ME, Cruickshanks KJ, Klein BE, Klein R, Schubert CR, Wiley TL. Multiple sensory impairment and quality of life. Ophthalmic Epidemiol. 2009;16:346-353. doi:10.3109/09286580903312236.

10. Deal JA, Betz J, Yaffe K, et al.; Health ABC Study Group. Hearing impairment and incident dementia and cognitive decline in older adults: The Health ABC Study. J Gerontol A Biol Sci Med Sci. 2017;72:703-709. doi:10.1093/gerona/glw069.

11. Millán-Calenti JC, Tubío J, Pita-Fernández S, et al. Prevalence of functional disability in activities of daily living (ADL), instrumental activities of daily living (IADL) and associated factors, as predictors of morbidity and mortality. Arch Gerontol Geriatr. 2010;50:306-310. doi:10.1016/j. archger.2009.04.017.

12. Aartolahti E, Häkkinen A, Lönnroos E, Kautiainen H, Sulkava R, Hartikainen S. Relationship between functional vision and balance and mobility performance in community-dwelling older adults. Aging Clin Exp Res. 2013;25:545-552. doi:10.1007/s40520-013-0120-z.

13. Daien V, Peres K, Villain M, Colvez A, Carriere I, Delcourt C. Visual acuity thresholds associated with activity limitations in the elderly. The Pathologies Oculaires Liées à l'Age study. Acta Ophthalmol. 2014;92:e500-e506. doi:10.1111/aos.12335.

14. Wallhagen MI, Strawbridge WJ, Shema SJ, Kurata J, Kaplan GA. Comparative impact of hearing and vision impairment on subsequent functioning. J Am Geriatr Soc. 2001;49:1086-1092.

15. Christ SL, Zheng DD, Swenor BK, et al. Longitudinal relationships among visual acuity, daily functional status, and mortality: the Salisbury Eye Evaluation Study. JAMA Ophthalmol. 2014;132:1400-1406. doi:10.1001/jamaophthalmol.2014.2847.

16. Chen DS, Genther DJ, Betz J, Lin FR. Association between hearing impairment and self-reported difficulty in physical functioning. J Am Geriatr Soc. 2014;62:850-856. doi:10.1111/jgs.12800.

17. Heine C, Browning C. Dual sensory loss in older adults: a systematic review. Gerontologist. 2015;55:913-928. doi:10.1093/geront/gnv074.

18. Lutomski JE, Baars MA, Schalk BW, et al.; TOPICS-MDS Consortium. The development of the Older Persons and Informal Caregivers Survey Minimum DataSet (TOPICS-MDS): a large-scale data sharing initiative. PLoS One. 2013;8:e81673. doi:10.1371/journal.pone.0081673.

19. Lutomski JE, van Exel NJ, Kempen GI, et al. Validation of the carerelated quality of life instrument in different study settings: findings from The Older Persons and Informal Caregivers Survey Minimum DataSet (TOPICS-MDS). Qual Life Res. 2015;24:1281-1293. doi:10.1007/ s11136-014-0841-2.

20. Weinberger M, Samsa GP, Schmader K, Greenberg SM, Carr DB, Wildman DS. Comparing proxy and patients' perceptions of patients' functional status: results from an outpatient geriatric clinic. J Am Geriatr Soc. 1992;40:585-588.

21. Twisk JWR. Applied Longitudinal Data Analysis for Epidemiology: A Practical Guide. Cambridge: Cambridge University Press; 2003.

22. Zeger SL, Liang KY. Longitudinal data analysis for discrete and continuous outcomes. Biometrics. 1986;42:121-130.
23. Zeger SL, Liang KY, Albert PS. Models for longitudinal data: a generalized estimating equation approach. Biometrics. 1988;44:1049-1060.

24. Bleijenberg N, Zuithoff NPA, Smith AK, de Wit NJ, Schuurmans MJ. Disability in the individual ADL, IADL, and mobility among older adults: a prospective cohort study. J Nutr Health Aging. 2017;21:897-903. doi:10.1007/s12603-017-0891-6.

25. Brennan M, Horowitz A, Su YP. Dual sensory loss and its impact on everyday competence. Gerontologist. 2005;45:337-346.

26. Gopinath B, Schneider J, Hickson L, et al. Hearing handicap, rather than measured hearing impairment, predicts poorer quality of life over 10 years in older adults. Maturitas. 2012;72:146-151. doi:10.1016/j. maturitas.2012.03.010.

27. Jacobs JM, Hammerman-Rozenberg R, Maaravi Y, Cohen A, Stessman J. The impact of visual impairment on health, function and mortality. Aging Clin Exp Res. 2005;17:281-286.

28. Lutomski JE, Krabbe PF, den Elzen WP, et al.; TOPICS Consortium. Rasch analysis reveals comparative analyses of activities of daily living/ instrumental activities of daily living summary scores from different residential settings is inappropriate. J Clin Epidemiol. 2016;74:207-217. doi:10.1016/j.jclinepi.2015.11.006.

29. Dawes P, Dickinson C, Emsley R, et al. Vision impairment and dual sensory problems in middle age. Ophthalmic Physiol Opt. 2014;34:479-488. doi:10.1111/opo.12138.

30. Carioli J, Teixeira AR. Use of hearing AIDS and functional capacity in middle-aged and elderly individuals. Int Arch Otorhinolaryngol. 2014;18:249-254. doi:10.1055/s-0034-1368136.

31. Debray TP, Moons KG, Abo-Zaid GM, Koffijberg H, Riley RD. Individual participant data meta-analysis for a binary outcome: onestage or two-stage? PLoS One. 2013;8:e60650. doi:10.1371/journal. pone.0060650.

32. Burke DL, Ensor J, Riley RD. Meta-analysis using individual participant data: one-stage and two-stage approaches, and why they may differ. Stat Med. 2017;36:855-875. doi:10.1002/sim.7141.

33. Gell NM, Rosenberg DE, Demiris G, LaCroix AZ, Patel KV. Patterns of technology use among older adults with and without disabilities. Gerontologist. 2015;55:412-421. doi:10.1093/geront/gnt166.

34. Laitinen A, Sainio P, Koskinen S, Rudanko SL, Laatikainen L, Aromaa A. The association between visual acuity and functional limitations: findings from a nationally representative population survey. Ophthalmic Epidemiol. 2007;14:333-342. doi:10.1080/01658100701473713.

35. Thetford C, Bennett KM, Hodge S, Knox PC, Robinson J. Resilience and vision impairment in older people. J Aging Stud. 2015;35:37-48. doi:10.1016/j.jaging.2015.07.007.

36. Heyl V, Wahl HW. Managing daily life with age-related sensory loss: cognitive resources gain in importance. Psychol Aging. 2012;27:510-521. doi:10.1037/a0025471.

37. Hershberger PJ. Information loss: the primary psychological trauma of the loss of vision. Percept Mot Skills. 1992;74:509-510. doi:10.2466/ pms.1992.74.2.509. 